\title{
Cardiac Compartment-specific Overexpression of a Modified Retinoic Acid Receptor Produces Dilated Cardiomyopathy and Congestive Heart Failure in Transgenic Mice
}

\author{
Melissa C. Colbert, ${ }^{*}$ D. Greg Hall, ${ }^{\ddagger}$ Thomas R. Kimball, ${ }^{\S}$ Sandra A. Witt, ${ }^{\S}$ John N. Lorenz," Margaret L. Kirby, \\ Timothy E. Hewett, ${ }^{\star}$ Raisa Klevitsky, ${ }^{*}$ and Jeffrey Robbins ${ }^{\star}$ \\ *Division of Molecular Cardiovascular Biology, Children’s Hospital Research Foundation, Cincinnati, Ohio 45229-3039; ${ }^{\ddagger}$ Department of \\ Pathology, The University of Georgia College of Veterinary Medicine, Athens, Georgia 30602; Division of Cardiology, Children's \\ Hospital Medical Center, Cincinnati, Ohio 45229; "Department of Molecular and Cellular Physiology, University of Cincinnati College of \\ Medicine, Cincinnati, Ohio 45267; "IDepartment of Anatomy and Cell Biology, Developmental Biology Program, Institute of Molecular \\ Medicine and Genetics, Medical College of Georgia, Augusta, Georgia 30912
}

\begin{abstract}
Retinoids play a critical role in cardiac morphogenesis. To examine the effects of excessive retinoid signaling on myocardial development, transgenic mice that overexpress a constitutively active retinoic acid receptor (RAR) controlled by either the $\alpha$ - or $\beta$-myosin heavy chain (MyHC) promoter were generated. Animals carrying the $\alpha$-MyHC-RAR transgene expressed RARs in embryonic atria and in adult atria and ventricles, but developed no signs of either malformations or disease. In contrast, $\beta$-MyHC-RAR animals, where expression was activated in fetal ventricles, developed a dilated cardiomyopathy that varied in severity with transgene copy number. Characteristic postmortem lesions included biventricular chamber dilation and left atrial thrombosis; the incidence and severity of these lesions increased with increasing copy number. Transcript analyses showed that molecular markers of hypertrophy, $\alpha$-skeletal actin, atrial natriuretic factor and $\beta-\mathrm{MyHC}$, were upregulated. Cardiac performance of transgenic hearts was evaluated using the isolated perfused working heart model as well as in vivo, by transthoracic M-mode echocardiography. Both analyses showed moderate to severe impairment of left ventricular function and reduced cardiac contractility. Thus, expression of a constitutively active RAR in developing atria and/ or in postnatal ventricles is relatively benign, while ventricular expression during gestation can lead to significant cardiac dysfunction. (J. Clin. Invest. 1997. 100:1958-1968.) Key words: retinoic acid receptors - transgenic mice $\bullet$ left ventricular function • dilated cardiomyopathy $\bullet$ heart failure
\end{abstract}

\section{Introduction}

Heart failure, a major consequence of cardiovascular disease, afflicts $\sim 4.7$ million Americans alone resulting in enormous costs for care and treatment (1). While major advances have

Address correspondence to Melissa C. Colbert, Ph.D., Division of Molecular Cardiovascular Biology, The Children's Hospital Research Foundation, 3333 Burnet Avenue, Cincinnati, OH 45229-3039. Phone: 513-636-7057; FAX: 513-636-5958; E-mail: melissa.colbert@chmcc.org

Received for publication 12 April 1997 and accepted in revised form 17 August 1997.

J. Clin. Invest.

(C) The American Society for Clinical Investigation, Inc. 0021-9738/97/10/1958/11 \$2.00

Volume 100, Number 8, October 1997, 1958-1968

http://www.jci.org been made in diagnosis and treatment, the molecular etiology associated with specific cardiovascular diseases is just now being elucidated. Sarcomeric dysfunction is most often associated with diastolic failure and hypertrophy, and a number of different mutations in sarcomeric proteins can cause familial hypertrophic cardiomyopathy (FHC; for review see reference 2 ). Recent studies have shown that a variety of molecular changes appear to affect systolic function and produce dilated cardiomyopathy (DCM). ${ }^{1}$ Mutations in dystrophin (3) and myotonin protein kinase (4) have been linked to familial DCM associated with Becker/Duchenne muscular dystrophy and myotonic dystrophy. Loss-of-function studies with muscle LIM protein (5) and desmin- (6) deficient mice, or gain-of-function analysis in transgenics overexpressing diverse gene products, such as polyoma virus large $\mathrm{T}$ (7), Epstein-Barr virus nuclear antigen-leader protein (8), and $\mathrm{G}_{\mathrm{s}} \alpha(9)$, can also reproduce aspects of DCM.

Retinoic acid (RA), the active metabolite of vitamin A, plays a significant role in regulating cardiac form and function throughout the life of the organism. Both cardiac morphogenesis and myocardial differentiation are affected by alterations in RA homeostasis. During the early stages of cardiogenesis, excess RA affects folding and septation of the outflow tract and cardiac chambers (10). Conotruncal malformations, such as double outlet right ventricle, transposition of the great arteries, tetralogy of Fallot, supracristal ventricular septal defect, and truncus arteriosus are common in cases of human retinoic acid embryopathy (11). Molecular correlates for Wilson and Warkany's seminal studies of vitamin A deficiency-associated cardiovascular defects (12) are becoming apparent using retinoid receptor gene ablations which demonstrated that expansion of the compact layer of the heart is also critically dependent upon retinoids during midgestation (13-15). More recent in vitro data suggest that RA suppresses endothelin- and phenylephrine-mediated myocardial hypertrophy $(16,17)$. Thus the retinoids may have an important role in the adult heart as well.

1. Abbreviations used in this paper: $\beta$-gal; $\beta$-galactosidase; DCM, dilated cardiomyopathy; dpc, days post coitum; GAPDH, glyceraldehyde 3-phosphate dehydrogenase; hRAR $\alpha$-CB, human RAR $\alpha$ collagen $\beta$-galactosidase; $h_{s}, L V$ thickness; $L V$, left ventricular or ventricle; LVED, LV end-diastolic; LVES, LV end-systolic; MyHC, myosin heavy chain; RA, retinoic acid; RAR, retinoic acid receptor; $\mathrm{RXR}$, retinoid $\mathrm{X}$ receptor; SEM, scanning electron microscopy; SERCA, sarcoplasmic reticulum calcium ATPase; VCFc, velocity of fiber shortening, corrected for heart rate; $+d P / d t$, the first derivative of the decrease in left ventricular systolic pressure with respect to time, a measure of contractility. 
The pleiotropic effects of RA are mediated by two families of nuclear receptors, the RA receptors (RARs) and retinoid X receptors (RXRs). RXRs bind the 9-cis congener of RA exclusively while the RARs can be activated by both all trans and 9-cis RA. These receptors are modular in structure and, based on homology within the DNA binding domain, have been classified as members of the nuclear receptor superfamily of ligand-activated transcription factors. A highly complex set of interactions exists between the receptors, specific ligands, and DNA target sequences or response elements within the promoter regions of retinoid sensitive genes (for review see reference 18). RARs and RXRs form dimers in vitro, either homodimers between the RXRs or RXR-RAR heterodimers. Significantly, the RXRs act as dimerization partners for a number of other members of the superfamily including thyroid hormone receptors and vitamin D receptors. Depending upon the receptor combination, the availability of ligand and the orientation of the dimer pair on the DNA sequence, receptors can activate or inhibit transcription of specific target genes (for review see reference 19).

The modular nature of RARs makes them readily amenable to modification such that dominant negative (20) as well as constitutively active receptors (21) have been made. The use of tissue specific promoters for targeting these constructs, and the attendant effects of too little or too much RA to particular organs at various times during development in transgenic animals has been well documented (20-22). Thus one can examine the specific effects of the retinoid state-deficiency or excess - on the organ system of interest without the global effects RA has on development. In this study cardiac compartmentspecific overexpression of a constitutively active RAR (21) in the developing myocardium was achieved using the myosin heavy chain $(\mathrm{MyHC})$ promoters. Mice that carry the transgene under control of the $\alpha$-MyHC promoter are healthy and have no signs of morphologic abnormalities or disease. In contrast, $\beta$-MyHC-RAR animals develop a characteristic DCM that varies in severity with transgene copy number.

\section{Methods}

Transgene construction and production of mice. The construction and constitutive activity of the chimeric hRAR $\alpha$ transgene has been described previously; it consists of a human RAR $\alpha$ truncated at amino acid 448 that was then fused, in frame, via a small collagen linker to bacterial $\beta$-galactosidase ( $\beta$-gal) $(21,23)$. The $\alpha$-MyHC-human RAR $\alpha$ collagen $\beta$-galactosidase (hRAR $\alpha-\mathrm{CB})$ construct and mice have been described (24); the $\beta$-MyHC-RAR construct was made by inserting the human $\mathrm{RAR} \alpha$-collagen $\beta$-gal transgene (21) into a plasmid vector containing the $\beta$-MyHC promoter and simian virus 40 (SV40) splice and polyadenylation sequences ( $\beta$-MyHC-hRAR $\alpha-\mathrm{CB})$. The construct was prepared for microinjection as described previously; founder animals of both lines were identified by PCR screening using primers for $\beta$-gal (25). Embryos were generated from timed matings between transgenic sires and nontransgenic dams and stained for $\beta$-gal activity (25). Embryos or excised hearts were routinely incubated in substrate at room temperature overnight to allow for maximum color development, however, in line 30 (see below) $\beta$-gal activity was readily detected after $3 \mathrm{~h}$ of incubation.

Histopathology analyses. Mice were killed by pentobarbital overdose and necropsied immediately. Body weights were obtained before dissection. Hearts were removed, rinsed briefly to evacuate blood from the chambers, and then weighed. Tissues were fixed by immersion in either $4 \%$ paraformaldehyde, acid-alcohol, or $10 \%$ neutral-buffered formalin, processed routinely for paraffin embedding
(26) and 5- $\mu \mathrm{m}$ sections were stained with hematoxylin and eosin. Photomicrographs were taken on an Olympus Vanox-S Model AHBS Research Microscope. For scanning electron microscopy (SEM), the left ventricular free wall was dissected from fresh hearts and immersed in $4 \%$ paraformaldehyde in PBS. The samples were dehydrated in ethanol and critical point dried (Tousimis Sandri-790) with liquid carbon dioxide, sputter-coated with a 15-20 nm layer of gold (Technics Hummergold), examined and photographed using a Phillips XL-30 FEG scanning electron microscope.

Quantitative RNA analysis. RNA was isolated from hearts and the different transcript species quantitated as described previously (27). Transcript-specific oligonucleotides used in these analyses included glyceraldehyde 3-phosphate dehydrogenase (GAPDH), $\alpha$-MyHC, $\beta$-MyHC, $\alpha$-cardiac actin, $\alpha$-skeletal actin, the sarcoplasmic reticulum $\mathrm{Ca}^{2+}$ ATPase (SERCA), phospholamban, and atrial natriuretic factor (ANF) (28). The following transcript-specific oligonucleotides were also generated and used: TR $\alpha 1$; 5'-GCACTCGACTTTCATGTGGAGGAAGCGGCTGGCGTGGCAG; TR $\alpha 2$; 5'-GACCCTGAACAACATGCATTCCGAGAAGCTGCTGTCCCTCC. RNA levels were quantitated using a PhosphorImager (Image Quant v3.3 software; Molecular Dynamics, Sunnyvale, CA) and differences in loading corrected and normalized to the GAPDH signal.

Echocardiography and hemodynamic measurements. Mice were anesthetized with inhaled isofluorane or with intraperitoneal injections of ketamine $(50 \mu \mathrm{g} / \mathrm{g}$ body weight) and thiobutabarbital (100 $\mu \mathrm{g} / \mathrm{g}$ body weight). The ventral chest was shaved and the animal placed on a thermally-controlled table in a custom fashioned foam bed in a slight left lateral decubitus lie. Body temperature was continually monitored via rectal probe and maintained at $37^{\circ} \mathrm{C}$. Echocardiography was performed using a Hewlett Packard Sonos 2500 Ultrasound System equipped with a $7.5-\mathrm{MHz}$ transducer (Hewlett Packard, Andover, MA). In order to place the heart in the mid-field of the ultrasound sector where axial resolution is optimal, the transducer was fashioned with a latex balloon filled with warm acoustic gel producing a 1-cm standoff between the chest wall and the transducer face. A layer of warm acoustic gel was applied to the left hemithorax and the probe placed on the chest carefully avoiding excessive pressure. Two dimensionally-guided M-mode echocardiography of the left ventricle from its short axis was recorded on both $1 / 2$ inch S-VHS tape and a strip chart at a speed of $100 \mathrm{~mm} / \mathrm{s}$.

For measurement of pressure indices, mice anesthetized as above were allowed to breathe spontaneously through a tracheotomy created by surgical placement of a short length of polyethylene tubing. The right femoral artery was cannulated using custom fashioned polyethylene tubing pulled to a small diameter from 0.25 -inch OD thick-walled tubing that was then connected to a COBE CDXIII Pressure Transducer (COBE Cardiovascular, Inc., Arvada, CO). Using the same type of small-diameter tubing, the right femoral vein was cannulated with three separate catheters connected to a CMA/100 Microinjection pump for infusion of experimental drugs. The left ventricle was then cannulated via the right carotid artery with a $1.8-\mathrm{F}$ Millar MIKRO-TIP transducer with continuous monitoring of the pressure wave form. This high-fidelity transducer has a tip diameter of $\sim 0.60 \mathrm{~mm}$, a frequency response that is flat to $10,000 \mathrm{~Hz}$ and, therefore, provides accurate monitoring of the high frequency murine ventricular pressure pulse (29). After surgery, all wounds were closed using cyanoacrylate to minimize evaporative fluid loss and the mice were stabilized for 30-45 min. The ventricular pressure waveform was inputted into the ultrasound system and superimposed directly on the echocardiographic image. Signals were also simultaneously recorded using MacLab hardware and software.

Echocardiography was performed at eight study times in each mouse as follows. Baseline contractility was assessed by performing echocardiography at three different afterload states: (\#1) at baseline before administration of any experimental drugs; (\#2) during phenylephrine administration ( $40 \mathrm{ng} / \mathrm{g}$ per minute) to increase afterload; (\#3) during nitroprusside (10 $\mathrm{ng} / \mathrm{g}$ per minute) administration to decrease afterload; (\#4) after these experimental drugs had been discon- 
tinued and ventricular pressure returned to baseline levels. Dobutamine was administered and contractility at the higher inotropic state assessed by echocardiography at three different afterload states: (\#5) during dobutamine infusion (16 ng/g per minute) alone; (\#6) during dobutamine and phenylephrine infusion; (\#7) during dobutamine and nitroprusside infusion. The eighth and final echocardiographic examination took place after all drugs were discontinued and ventricular pressure returned to baseline levels. At each study time, left ventricular end-diastolic and end-systolic dimension and thickness (LVED, LVES, $h_{d}, h_{s}$, respectively), end-diastolic septal thickness $\left(\mathrm{s}_{\mathrm{d}}\right.$ ), ejection time (ET), and the RR interval were measured from the M-mode echocardiogram. End-diastole was defined as the initial portion of the upstroke of the superimposed left ventricular pressure trace. End-systole was defined as the smallest left ventricular dimension. Three consecutive cardiac cycles were measured in each mouse at each study time. Pressure-volume loops were generated by digitizing the ventricular pressure waveform, septum, and posterior wall (Curve Analysis; Digisonics, Houston, TX). This software generates ventricular pressure and dimension data pairs at $1 \mathrm{~ms}$ intervals for the entire cardiac cycle which were plotted graphically as $(\mathrm{x}, \mathrm{y})$ data pairs to develop the pressure-dimension loop. The end-systolic pressure $\left(\mathrm{P}_{\mathrm{es}}=\right.$ the pressure immediately before isovolumic relaxation) was calculated from the loop.

The following measurements were made by one investigator (T.R. Kimball) blinded to transgenic status: left ventricular mass $\left(\mathrm{LV}_{\text {mass }}\right.$ in $\left.\mathrm{mg}\right)=[0.8][1.04]\left[\left(\mathrm{LVED}+\mathrm{h}_{\mathrm{d}}+\mathrm{s}_{\mathrm{d}}\right)^{3}-(\mathrm{LVED})^{3}\right]$. Ejection phase indices: shortening fraction $(\mathrm{SF}=[(\mathrm{LVED}-\mathrm{LVES}) /$ LVED][100]) and heart rate-corrected velocity of circumferential fiber shortening $\left(\mathrm{VCF}_{\mathrm{c}}=(\mathrm{SF})\left(\mathrm{RR}^{0.5}\right) / \mathrm{ET}\right)$ were calculated to assess LV performance. These indices reflect overall left ventricular systolic performance and, like all ejection phase indices, depend not only on left ventricular contractility but also on loading conditions. Therefore, indices that measure contractility independent of loading conditions were also calculated. Left ventricular afterload was measured by calculation of end-systolic wall stress, a reliable index of left ventricular afterload, using the following equation: wall stress (WS) in $\mathrm{g} / \mathrm{cm}^{2}=$ (1.35) $(\mathrm{LVES})\left(\mathrm{P}_{\mathrm{es}}\right) /(4)\left(\mathrm{h}_{\mathrm{s}}\right)\left[1+\mathrm{h}_{\mathrm{s}} /\right.$ LVES $\left.)\right]$. Left ventricular contractility. End-systolic pressure and dimension data pairs were calculated from the pressure-dimension loops. Baseline contractility was assessed by determining the regression line from the 3 pressure-dimension data pairs generated at study times \#1 (baseline), \#2 (phenylephrine), and \#3 (nitroprusside). Contractile state during dobutamine was assessed by determining the regression line from the three data pairs generated at study times \#5 (dobutamine alone), \#6 (dobutamine and phenylephrine), \#7 (dobutamine and nitroprusside). From each regression line, slope- and y-intercept were determined. Contractility was also assessed by determining the stress-velocity relationship at end-systole. Specifically, the left ventricular VCFc, WS data pair were examined at each study time. Baseline contractility was assessed by determining the regression line from the three stressvelocity data pairs generated at study times \#1, \#2, and \#3. Contractility during dobutamine was assessed by determining the regression line from the three data pairs generated at study times \#5, \#6, and \#7.

\section{Results}

Production of $\alpha$ - and $\beta-M y H C-h R A R \alpha-C B$ transgenic mice. In mice, the linked $\alpha$ - and $\beta$-MyHC genes are cardiac compartment specific and antithetically regulated throughout the life of the animal (30). The promoter regions for these genes have been cloned, extensively characterized, and used to express a number of transgenes in the heart. The $\alpha$-MyHC promoter used in this study is activated in the primitive atria by $9.5 \mathrm{~d}$ post coitum (dpc) and maintains expression in this compartment in both the embryo and adult (24). In the neonatal ventricle, transgene expression is activated shortly after birth mimicking endogenous $\alpha-\mathrm{MyHC}$ expression. In contrast, the
Table I. Comparison of hRAR $\alpha-C B$ Transgenic Lines

\begin{tabular}{lcc}
\hline & $\alpha$-MyHC promoter & $\beta$-MyHC promoter \\
\hline Animals screened & 34 & 101 \\
F $_{\mathrm{O}}$ identified & 10 & 9 \\
$\beta$-gal expression & 5 & 3 \\
Phenotype & None & DCM \\
& & \\
\hline
\end{tabular}

$\mathrm{F}_{\mathrm{O}}$, founder generation.

$\beta$-MyHC promoter construct directs transgene expression predominantly in the fetal ventricles during development and to a lesser extent in the developing atria (depending upon copy number, see below). In order to easily correlate the effects of excess retinoid signaling with transgene expression on myocardial development, multiple lines of transgenic mice carrying a constitutively active human RAR fused to the bacterial lac $Z$ (21) under control of the $\alpha$ - or $\beta$-MyHC promoters were generated (see Methods). For the $\alpha$-MyHC promoter construct, nearly $30 \%$ of the potential founders were transgene positive and $50 \%$ of these had high levels of cardiac $\beta$-gal activity (Table I). No abnormalities in cardiac morphogenesis or heart size were grossly apparent at any developmental stage (for developmental $\beta$-gal expression see reference 24$)$; cardiac histology was also unremarkable (e.g., see Fig. $3 B$ ). The animals were healthy, without unusual morbidity or mortality, bred normally, and produced litters of normal size. It appears, therefore, that excess RA signaling in developing atria or in postnatal atria and ventricles does not produce overtly detectable abnormalities.

The $\beta$-MyHC-hRAR $\alpha-\mathrm{CB}$ transgenic mice are in striking contrast to the above animals. Only $3 / 101$ potential founders (lines 30, 32, 50; Tables I and II) had significant cardiac $\beta$-gal activity. All F1 animals produced by line 50 died by 6 mo of age and no F2 animals could be derived. The litters of this female founder were approximately half-size and approximately one animal per litter was transgene positive. This, and the low percentage of expressing founders, suggests that high level transgene expression in developing ventricles is embryonic lethal. The two remaining animals, 30 and 32, were outbred to nontransgenic mates, copy number determined by standard dot blot analyses (reference 31, Table II) and stable lines established (phenotypes described below).

Table II. Summary of $\beta-M y H C-h R A R \alpha-C B$ Transgenic Lines

\begin{tabular}{lccc}
\hline Line number & Copy number & $\beta$-gal expression & Phenotype \\
\hline 12 & 15 & + /-, Embryonic & None \\
17 & 4 & ND & None \\
26 & 95 & + /-, Embryonic & None \\
29 & 70 & ND & None \\
30 & 12 &,++ Embryonic & DCM \\
32 & 6 &,+ Embryonic & DCM \\
39 & 5 & ND & None \\
47 & 4 & ND & None \\
50 & 150 &,++++ Adult & DCM \\
& & &
\end{tabular}

$N D$, not detected. 

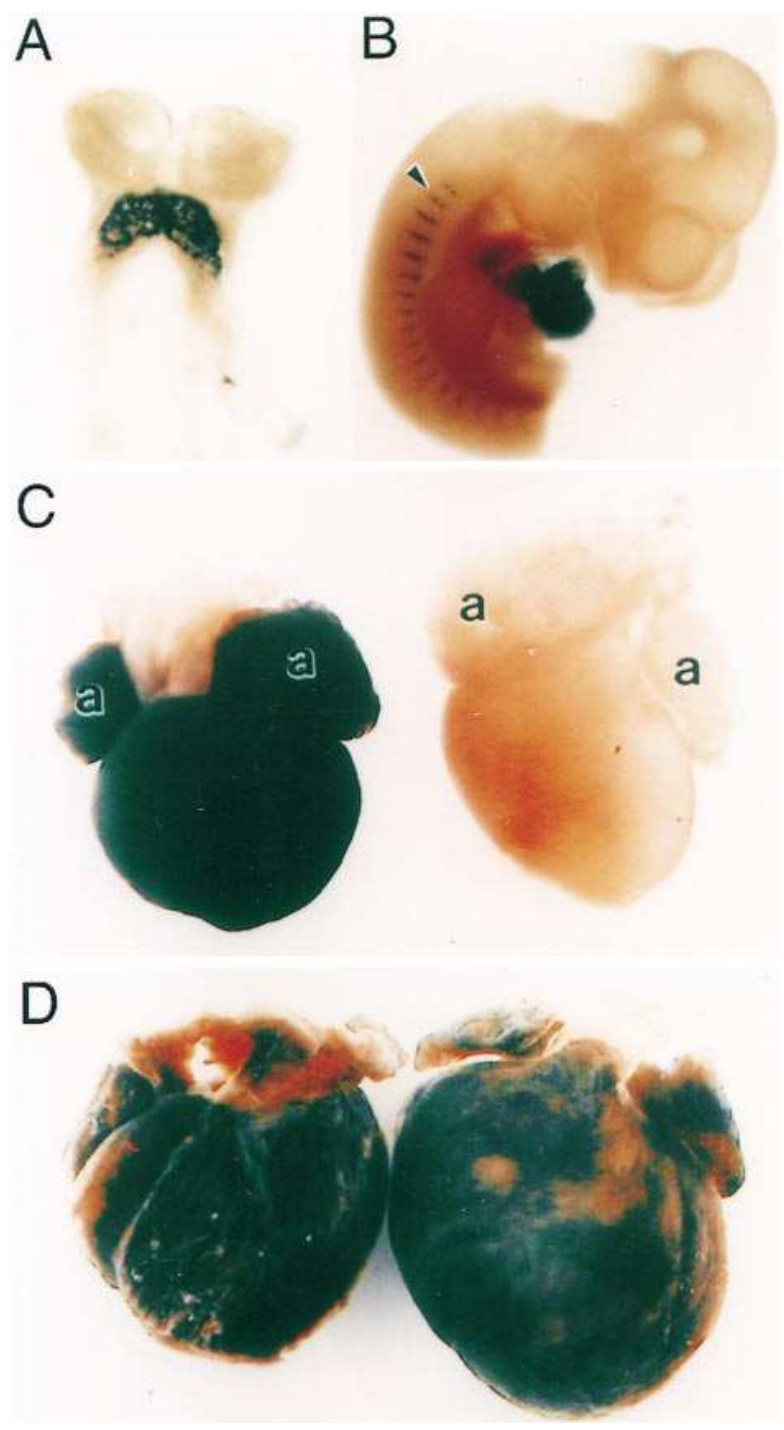

Figure 1. Developmental expression patterns of $\beta$-gal in $\beta$-MyHC line 30 transgenic mice. $(A) \beta$-gal activity is clearly present in the primitive heart tube of a 6-8 somite embryo. (B) By 10.5 dpc expression can be detected throughout the heart and in the myotomal half of the somites (arrowhead). (C) Fetal hearts at 17.5 dpc show strong $\beta$-gal staining and appear more globose than the controls (unstained). $(D)$ Expression in the adult ( $>8 \mathrm{wk}$ ) hearts is maintained. $a$, atria.

$\beta$-MyHC-receptor transgene expression leads to cardiac $a b$ normalities. Transgene expression, indicated by myocardial $\beta$-gal staining, was first detected in cells of the primitive heart tube in 6-8 somite embryos of lines 30 (Fig. $1 A$ ) and 32 (data not shown). At $10.5 \mathrm{dpc}$ the primitive left ventricle stained heavily; outflow tract and atria were also positive (Fig. $1 \mathrm{~B}$ ). Both atria and ventricles were intensely positive for $\beta$-gal activity at $17.5 \mathrm{dpc}(\mathrm{Fig} .1 \mathrm{C}$ ) when the endogenous $\beta$-MyHC promoter reaches maximal activity (30). At $15 \mathrm{dpc}$ and continuing throughout fetal and early postnatal stages, transgenic hearts were more globose than nontransgenic hearts (compare stained and unstained hearts in Fig. 1C). Furthermore, strong $\beta$-gal activity was present in both cardiac compartments of neonatal and $2 \mathrm{wk}$ postnatal hearts (data not shown). This expression pattern is aberrant compared to both the endogenous $\beta$-MyHC gene and other transgenic reporters used with this promoter (32). Developmental downregulation of the transgenic promoter is copy number-dependent; if $\leq 24$ copies per genome are present, expression is largely restricted to the ventricle and is shut down at or around birth (31). Line 30 has 12 copies of the transgene and therefore should downregulate ventricular expression postnatally. In $\beta$-MyHC transgenics, however, $\beta$-gal expression persists throughout the atria and ventricles even in adults in all three lines of affected mice (Fig. $1 D$ ). Thus it appears that expression of the mutated RAR directly or indirectly affects the transgenic $\beta$-MyHC promoter activity during development.

Both the age of onset and severity of the phenotype varied with transgene copy number; the pathologies are shown in Figs. 2 and 3. Line 50 (150 copies) males and females showed poor to no mating behavior and the line was lost within $12 \mathrm{mo}$. Clinical signs of distress, characterized by labored breathing and rough haircoat, developed by 4-6 mo of age in $8 / 8$ animals. At necropsy, typical gross lesions included serosanguinous pleural effusion, pulmonary congestion and edema, cardiomegaly due to biventricular dilation with thinning of ventricular walls, and chronic left atrial thrombosis (Fig. 2, $A$ and $B$ ). Microscopic cardiac lesions included marked myofiber hypertrophy, characterized by increased fiber diameter with large irregularly-shaped nuclei (karyomegaly), mild to moderate myocardial fibrosis, and mild myofiber sarcoplasmic vacuolation (Fig. 3 E).

Line 30 males (12 copies) older than 4-6 mo were unable to breed successfully. Females usually deliver one litter but died before or shortly after delivering a second consecutive pregnancy. 7 of 27 animals aged 4 mo or older developed clinical signs similar to those described for line 50 or died during stress-inducing activities such as anesthesia or transportation (Fig. $2 \mathrm{D}$ ). At necropsy severe biventricular dilation and atrial thrombosis were typically observed; these also presented in two animals without apparent clinical symptoms. SEM clearly revealed marked attenuation of papillary muscle and trabeculations associated with the interior surface of the left, but not the right, ventricle (Fig. 2, $E$ and $F$ ). Few details could be observed in the heavily muscled interior of the control left ventricle (Fig. $2 E$ ). In contrast, the walls of the transgenic heart (Fig. $2 F$ ) were thin, the chamber was very dilated, trabeculae and papillary muscles were much smaller, and the mitral valve leaflets were easily seen. Necropsies performed on a total of 25 apparently healthy mice (1-7 mo) showed mild cardiomegaly and no evidence of atrial thrombi (Fig. 4); there were no agerelated statistical differences in the onset of the hypertrophy. By $\sim 2$ mo of age, however, all examined hearts had histologic evidence of myofiber hypertrophy similar to changes described for line 50 hearts (Fig. 3, $D$ and $E$ ), which were increasingly pronounced with age. Therefore, morphologic and histopathologic changes, observed only in the ventricles, were apparent 2-3 mo before the onset of clinical symptoms.

No clinical signs of disease or obvious changes in breeding behavior other than those generally associated with aging were noted in line 32 (six transgene copies). Of 13 animals necropsied (5-16 mo), only 2 had atrial thrombosis and obvious cardiomegaly; neither animal had exhibited signs of distress. When compared to nontransgenic hearts (Fig. $3 A$ ), histologic evidence of myofiber hypertrophy was absent or very mild in 

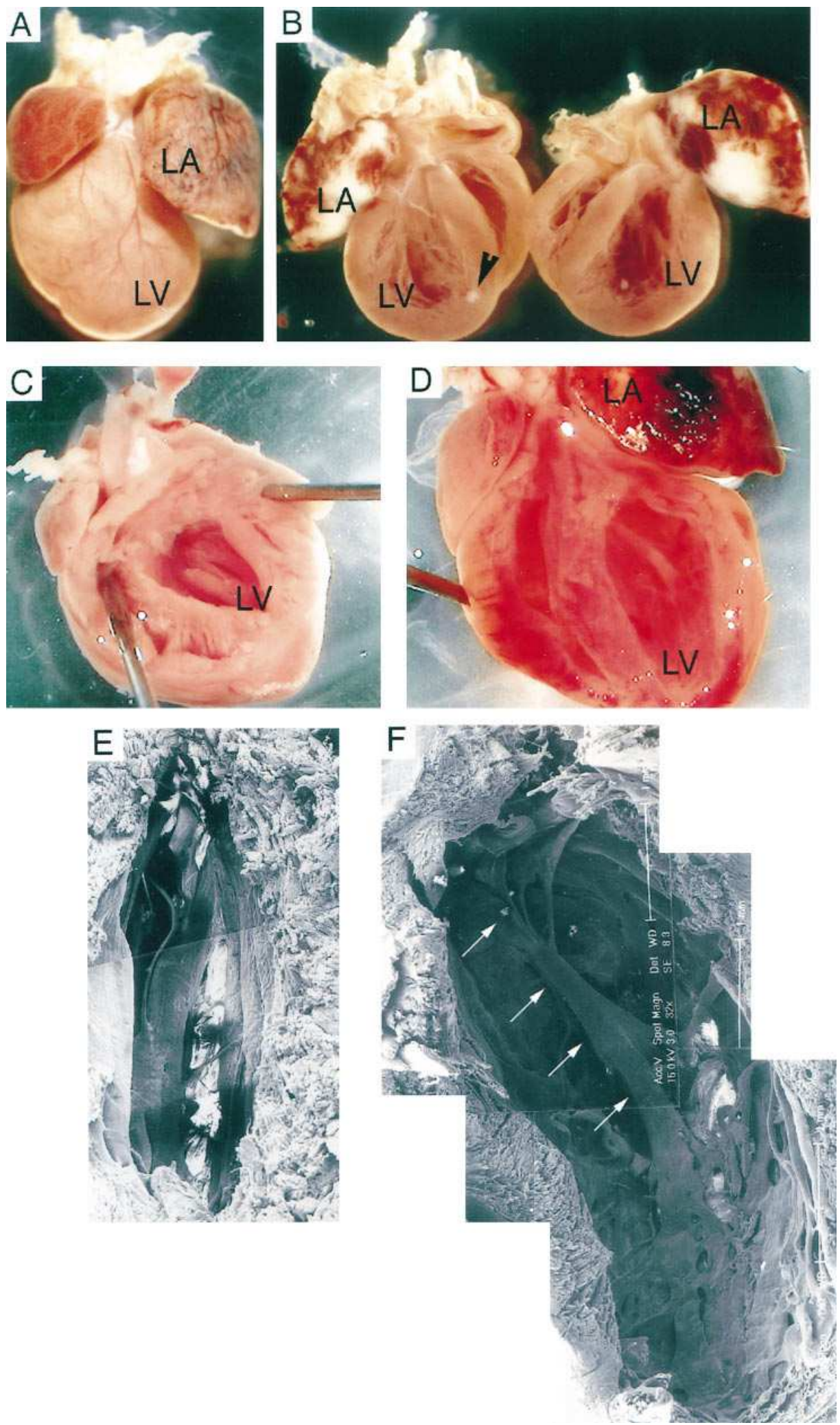

Figure 2. Gross pathology and SEM of $\beta$-MyHC-hRAR $\alpha$-CB transgenic hearts. (A) An intact, unfixed heart from a line-50 animal depicts a markedly enlarged left atrium ( $L A)$, enlarged and rounded LV and mildly enlarged right atrium. (B) The same heart opened longitudinally depicts a large chronic left atrial thrombus and dilated left ventricular chamber $(L V)$. The small white-tan nodule near the apex of the LV chamber is a small mural thrombus (arrowhead). The ventral wall was cut away from control $(C)$ and line $30(D)$ transgenic hearts to expose the interior of the ventricular chambers. Note the normal appearance of the papillary muscles within the LV chamber of the nontransgenic heart (C). (D) In contrast, the heart of the line-30 transgenic animal shows left ventricular dilation with attenuation of papillary muscles (see below) as well as large chronic left atrial thrombus. ( $E$ and $F$ ) Scanning electron micrographs show the interior landscape of the left ventricle of the same control $(E)$ and transgenic hearts $(F)$. Arrows mark the course of the remaining papillary muscle. Hearts for SEM were photographed at the same magnification $(\times 32)$. line 32 (Fig. $3 C$ ), although heart weight to body weight ratios were higher than in control animals (Fig. 4).

Molecular markers of hypertrophy and failure. On the basis of the morphologic data and heart weight/body weight ra- tios (Fig. 4), it appeared likely that molecular markers of myocardial hypertrophy, as represented by activation of the fetal gene program and elevated transcript levels of $\beta-\mathrm{MyHC}, \mathrm{ANF}$, and $\alpha$-skeletal actin (33-35) might be present. RNA from indi- 

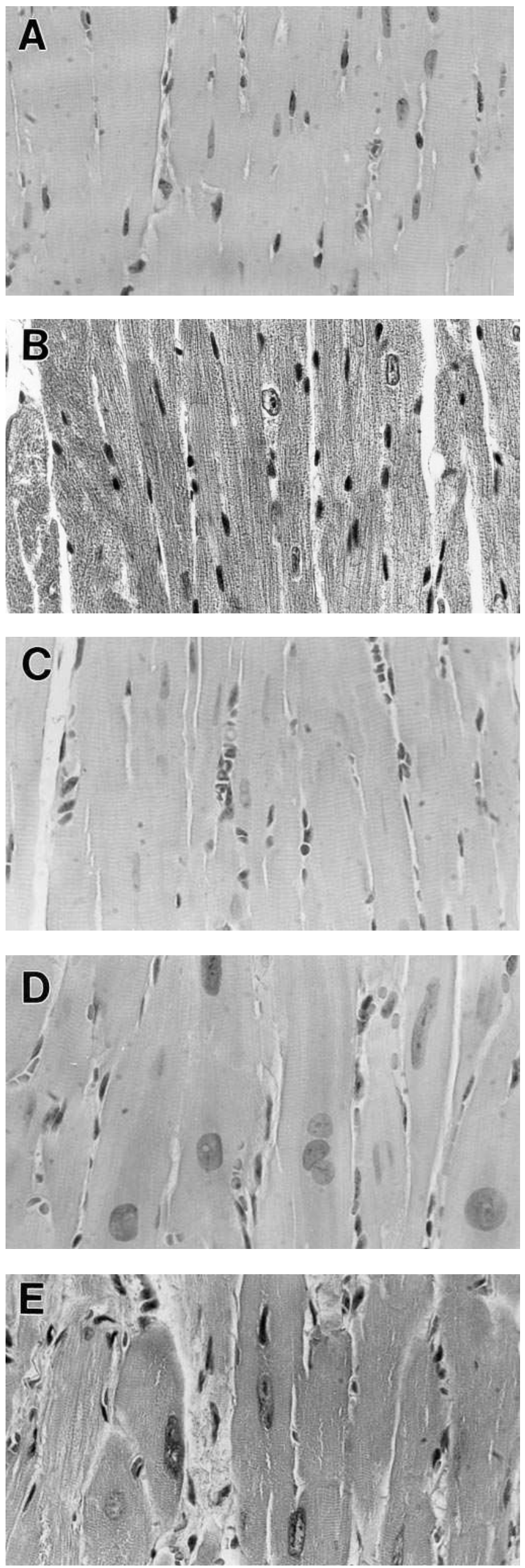

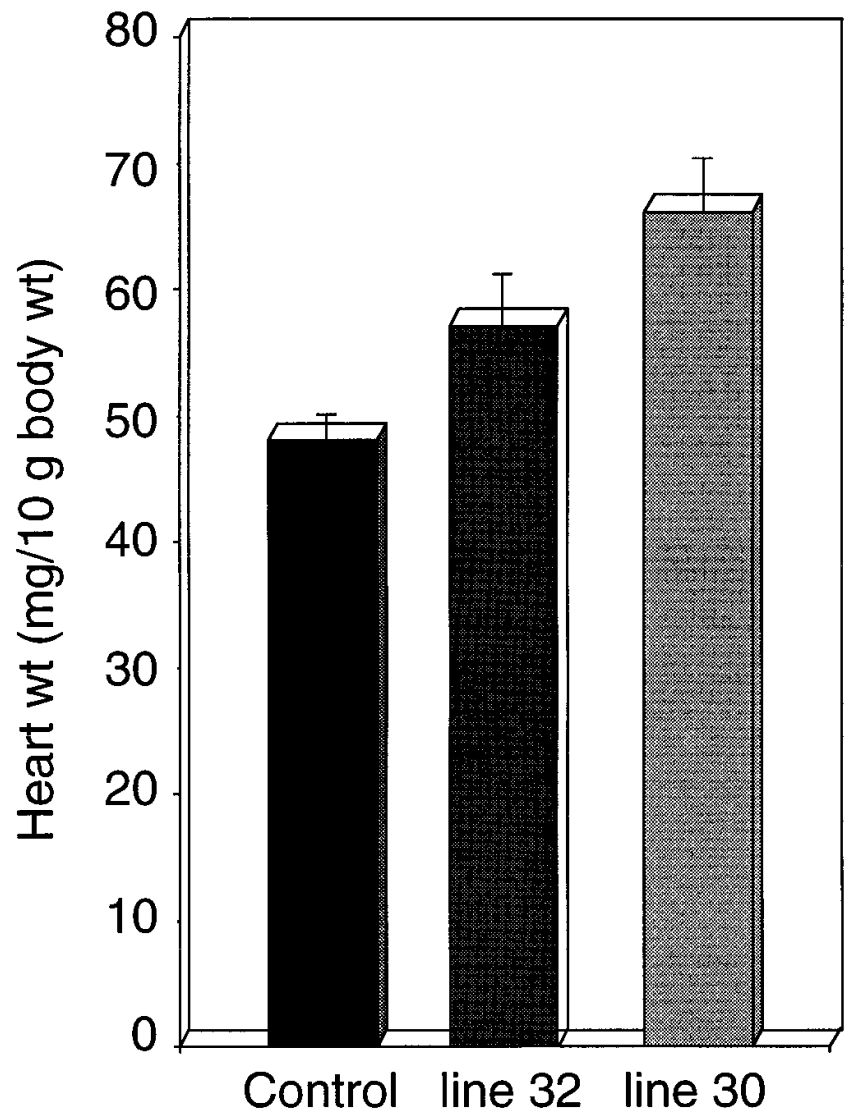

Figure 4. Hypertrophy varies in proportion to gene dosage. Heart weight to body weight ratios for lines 30 and 32 demonstrate hypertrophic changes that correlate with gene dosage. Heart weight to body weight ratios were determined for line 30 , line 32 , and control animals. The lowest copy number line, 32 (six transgene copies), shows an intermediate level of hypertrophy when compared to control and line 30 (12 transgene copies). Values are reported as mean; error bars indicate standard error of the mean. Control versus line 30, $P<0.0001$; control versus line $32, P \leq 0.0074$; line 30 versus line 32 $P \leq 0.0152$. Control, $n=25$; line $30, n=25$; line 32, $n=16$. A one way ANOVA was performed with Bonferroni post hoc testing for comparisons between the lines. Tests for significance, defined as $P \leq$ 0.0167, were performed using Statview 4.01 (Abacus Concepts Inc., Berkeley, CA).

vidual hearts derived from asymptomatic line 30 animals were subjected to quantitative dot blot analyses. Although asymptomatic, significant upregulation of each transcript was observed in transgenic animals compared to nontransgenic con-

Figure 3. Histopathology correlates with gene dosage. (A) Sections of control and $(B-E)$ transgenic hearts stained with hematoxylin and eosin were examined in similar areas of the interventricular septum near the LV chamber. ( $A$ ) Control, and (B) $\alpha$-MyHC-hRAR $\alpha \mathrm{CB}$ sections depict essentially indistinguishable myocardial histomorphology with normal myofiber diameter and myofiber nuclear morphology. $(C)$ Sections from line $32 \beta$-MyHC-RAR hearts indicate that hypertrophy was absent or very mild and well-defined sarcomeric striations are readily apparent. $(D)$ Line 30 and $(E)$ line 50 show moderate to marked myofiber hypertrophy characterized by increased myofiber diameter and significant variation in nuclear size and shape. Note the progressive loss of anisotropy from line $32(C)$ to line $30(D)$ to line $50(E)$. All animals were $\sim 5$ mo of age. All photomicrographs $(\times 440)$. 


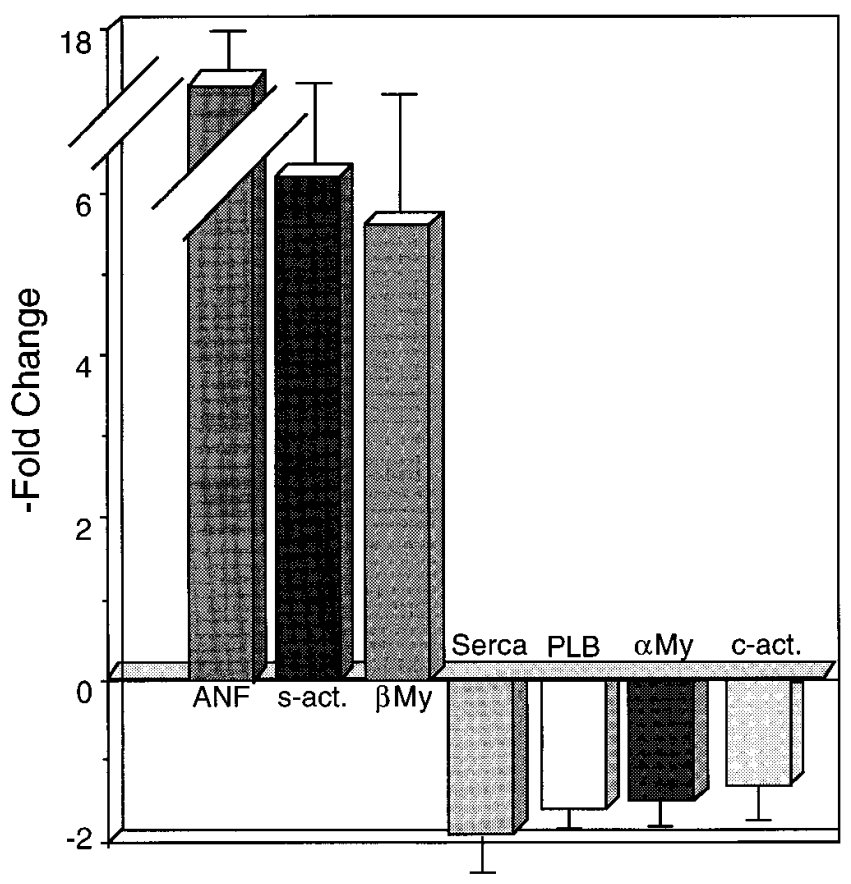

Figure 5. Molecular markers of hypertrophy. Cardiac specific gene expression was examined in line 30 hearts at $4-6$ mo of age. Ventricular RNA was analyzed by hybridizations to dot blots with transcriptspecific oligonucleotide probes (see Methods). Data were quantitated using a PhosphorImager, normalized to GAPDH and expressed as \pm fold increase/decrease compared to nontransgenics. Error bars indicate standard error of the mean. $n=7$.

trols (Fig. 5), even though they had yet to display overt signs of physical distress. A concomitant downregulation of $\alpha$-cardiac actin and $\alpha$-MyHC isoforms, normally observed during hypertrophy, also occurred. Sensitive markers for cardiac failure include the SERCA and phospholamban transcripts; both are downregulated in models of cardiac failure $(36,37)$ as alterations occur in the myocardial $\mathrm{Ca}^{2+}$-handling apparatus of failing hearts. Both of these transcripts are significantly decreased in transgenic hearts (Fig. 5) indicating that before overt signs of distress the hearts are already functionally compromised and conversion to decompensated failure may be in progress.

Cardiac physiology. To delineate the phenotype more precisely, cardiovascular function, specifically left ventricular (LV) function, was evaluated using an isolated working heart model $(27,28)$. Control littermates and transgenic animals, 3-6 mo for line 30 and 5-7 mo for line 32, were used. To determine the extent with which transgenic hearts could tolerate increasing volume loads (venous return), the cardiac minute work was varied from $200-600(\mathrm{mmHg} \times \mathrm{ml} / \mathrm{min})$. In spite of identical loads, maximal rates of pressure development for lines 30 and 32 were reduced significantly compared with control hearts: the first derivative of the increase in left ventricular systolic pressure with respect to time, a measure of contractility $(+d P /$ $d t$ ), was reduced by $63 \%$ in line 30 hearts and $44 \%$ in line 32 hearts (Table III). Relaxation rates were also reduced: the first derivative of the decrease in left ventricular systolic pressure with respect to time, a measure of relaxation $(-d P / d t)$, was reduced by $64 \%$ in line 30 hearts and $42 \%$ in line 32 hearts. The
Table III. Means \pm Standard Error of the Mean of Measured Cardiac Parameters

\begin{tabular}{lccc}
\hline & Control & Line 30 & Line 32 \\
\hline & $n=10$ & $n=4$ & $n=8$ \\
& & & \\
Working heart & & & \\
$\quad$ Heart rate (beats per minute) & $315 \pm 5$ & $304 \pm 10$ & $312 \pm 6$ \\
$+d P / d t(\mathrm{mmHg} / \mathrm{ms})$ & $4890 \pm 125$ & $1816 \pm 67^{*}$ & $2718 \pm 123^{*}$ \\
$-d P / d t(\mathrm{mmHg} / \mathrm{ms})$ & $3363 \pm 53$ & $1204 \pm 53^{*}$ & $1962 \pm 102^{*}$ \\
& & & \\
\hline
\end{tabular}

$* P \leq 0.0001$, transgenic versus control, unpaired Student's $t$ test.

Frank-Starling relationships, increased minute work as a function of the rate of pressure development $(+d P / d t)$, were also examined to determine if there were significant differences in cardiac contractility. Control hearts showed a strong positive correlation of $+d P / d t$ to increased left ventricular minute work, exhibiting a classic Starling response (Fig. $6 \mathrm{~A}$ ). The Starling responses of transgenic hearts were compromised and, like the histopathologic phenotype, varied with transgene copy number. Line 32 hearts (six copies) showed a modest decrease in slope (Fig. $6 \mathrm{~B}$ ), although the correlation was statistically similar to the normal response to increased work load. In contrast, line 30 hearts (12 copies; Fig. 6 C) demonstrated severely impaired cardiac function and significantly decreased slope. It was not possible to analyze hearts from line 50 because of their severe pathology.

To further evaluate LV function in vivo, line 30 animals were subjected to transthoracic M-mode echocardiography, with and without direct measurement of LV pressure. The results of the echocardiographic studies (Table IV, Fig. 7) confirm that LV size and mass were significantly increased in line 30 versus control mice and conclusively demonstrate increased right ventricular chamber size as well (Fig. 7). The indices of LV systolic performance (shortening fraction and VCFc) were also significantly decreased compared to control (Table IV).

In human studies, LV volume measurements are typically combined with pressure measurements to generate a pressurevolume loop. In mice, calculating volume from M-mode and/or two dimensional echocardiographic measurements might result in significant errors because of geometric assumptions of these derivatives. Therefore, a ventricular pressure-dimension loop was derived at each study time by digitizing the ventricular pressure wave form, septum, and posterior wall (Fig. 8). Control and transgenic animals were assessed at baseline (Fig. $8 A$ ) and under conditions of increased (phenylephrine infusion, Fig. $8 \mathrm{~B}$ ) or decreased (nitroprusside infusion, Fig. $8 \mathrm{C}$ ) afterload. In all circumstances, the area circumscribed by the pressure-dimension loops, an index of total LV stroke work, was substantially reduced in line 30 animals compared to controls. Left ventricular contractility (Table V), as assessed by the pressure-dimension data at end-systole, was decreased in transgenic mice (a more shallow slope). Although this change did not reach statistical significance, it may be more of a reflection of the small sample size $(n=5)$ as values for transgenics were consistently worse than for controls. Some animals were too ill and did not survive the surgical procedure which contributed to the small sample number. Left ventricular contractility, as assessed by the relationship of fiber shortening to end- 

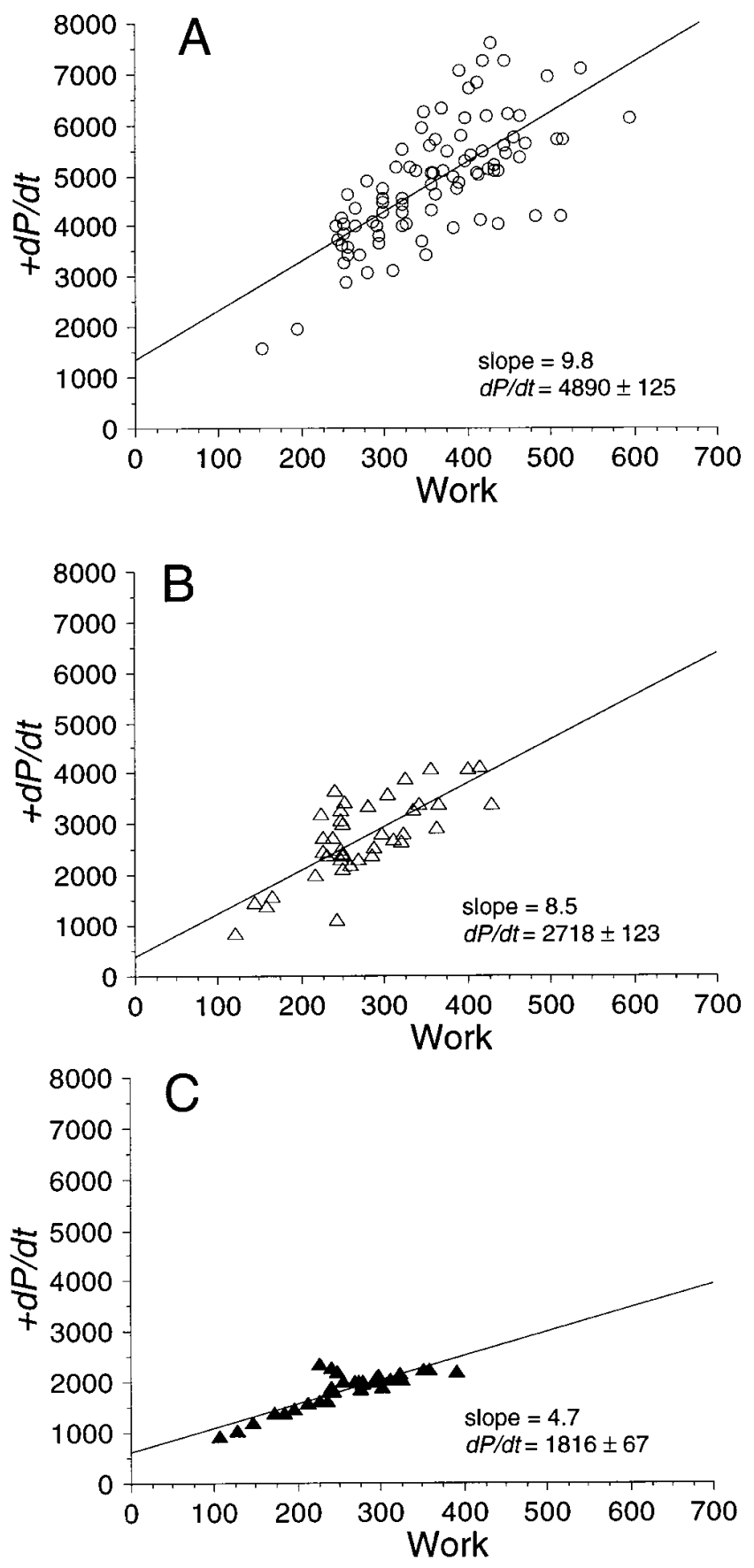

Figure 6. LV minute work and the rate of pressure development $(+d P / d t)$ in work performing hearts. The baseline recordings were taken under similar load conditions: mean aortic pressure (MAP, afterload), $50 \mathrm{mmHg}$; venous return, $\sim 5 \mathrm{ml} / \mathrm{min}$; $\mathrm{LV}$ minute work, $\sim 250 \mathrm{mmHg} \times \mathrm{ml} / \mathrm{min}$; heart rate, $300-390 \mathrm{bpm}$. The data were obtained by varying preload and afterload from $100-600(\mathrm{mmHg} \times \mathrm{ml} /$ $\min$ ). (A) Nontransgenic hearts (open circles, 88 measurements from 10 hearts; slope $=9.8, r=0.70, P<0.0001$ ) show a strong positive correlation of $+d P / d t$ to increased LV work. $(B)$ Line 32 (open triangles, 41 measurements from 8 hearts; slope $=8.5, r=0.75, P<$ 0.0001 ) show a more moderate positive correlation of $+d P / d t$ to increased left ventricular work. (C) Hearts from line 30 (closed triangles, 31 measurements from 4 hearts; slope $=4.7, r=0.04, P<0.0001$ ) show a significantly decreased response of $+d P / d t$ to increased left ventricular work. The slopes of the top and bottom regression curves are significantly different $(P<0.01)$. $r$ values are from a linear least
Table IV. Echocardiographic Indices

\begin{tabular}{lcc}
\hline \multicolumn{1}{c}{ Variable } & Control \pm SD & Line $30 \pm \mathrm{SD}$ \\
\hline & $n=8$ & $n=9$ \\
Heart rate & $407 \pm 50$ & $439 \pm 58$ \\
LV end-diastolic dimension (mm) & $3.4 \pm 0.4$ & $4.4 \pm 0.9^{*}$ \\
LV end-systolic dimension (mm) & $1.9 \pm 0.2$ & $3.3 \pm 0.8^{\ddagger}$ \\
LV posterior wall thickness (mm) & $0.6 \pm 0.2$ & $0.6 \pm 0.1$ \\
Septum (mm) & $0.7 \pm 0.1$ & $0.8 \pm 0.1$ \\
LV mass (g) & $49 \pm 20$ & $94 \pm 39^{*}$ \\
Indexed LV mass (mg/g body weight) & $1.9 \pm 0.8$ & $3.4 \pm 1.2^{\S}$ \\
Shortening fraction (percentage) & $43 \pm 7$ & $24 \pm 7^{\|}$ \\
VCFc (circ/s) & $2.4 \pm 0.6$ & $1.2 \pm 0.3^{\dddot{\pi}}$ \\
End-systolic wall stress (g/cm $\left.{ }^{2}\right)$ & $44 \pm 24$ & $73 \pm 27^{* *}$ \\
Ejection time (ms) & $71 \pm 8$ & $78 \pm 9$
\end{tabular}

${ }^{*} P<0.01 ;{ }^{\ddagger} P<0.0002 ;{ }^{\S} P<0.008 ;{ }^{\|} P<0.0001 ;{ }^{\mathbb{T}} P<0.0017 ; * * P<$ 0.10 ; control versus transgenic were compared using an unpaired Student's $t$ test.

systolic wall stress was significantly decreased in line 30 hearts, as shown by a parallel shift in the relationship down and to the left and reflected by a significantly lower y-intercept and no difference in slope. These findings are indicative of depressed left ventricular systolic performance and contractility in the transgenic mice.

With dobutamine administration, both groups of mice showed changes in the y-intercept of the end-systolic pressuredimension relationship indicative of increased contractility; however, this change reached statistical significance in control mice only (Table V). When contractility was assessed by endsystolic stress-velocity relationships, both groups of mice showed statistically significant increases in contractility with dobutamine reflected by increases in the y-intercepts. In addition, the slope of the relationship in the control mice significantly increased, indicating a shift of the hemodynamics towards decreased afterload.

\section{Discussion}

The cardiac compartment-specific effects of retinoid signaling are striking. Both transgenic constructs are expressed in the atria pre- and postnatally, yet there is no sign of atrial anatomic defects or impaired atrial function. The development of the atrial thrombus in the $\beta$-MyHC transgenics, like the effects on ventricular trabeculations and papillary muscle insufficiency, are secondary to ventricular dysfunction. Interestingly, in the $\operatorname{RXR} \alpha(13,14), \operatorname{RAR} / \operatorname{RAR}(15)$, or RXR/RAR $(14,38)$ gene knockout animals, the lack of RA signaling has little effect on atrial development or compartment-specific gene expression (39). Thus the atrial appendages appear to be insensitive to changes in retinoid status. However, ventricular morphogenesis and function are significantly affected by loss or gain of RA-mediated signaling. This is particularly apparent

squares fit of the data. A value of $P<0.05$ was considered statistically significant. 


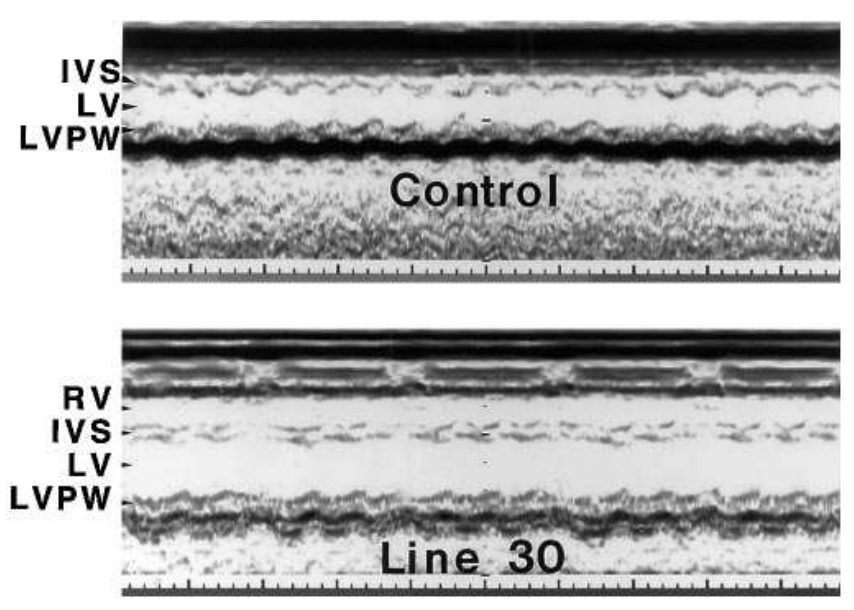

Figure 7. Transthoracic M-mode echocardiography. Representative tracings show significant dilation of both the left $(L V)$ and right $(R V)$ ventricle in a heart derived from a line-30 animal as compared to a control. No increases in left ventricular posterior wall width $(L V P W)$ or intraventricular (IVS) thicknesses were noted. See Table IV for a compilation of the measured indices.

in the vitamin A-deficient (12) and receptor-knockout models (13-15), which result in agenesis of the compact zone. These hearts have very thin myocardial walls and the embryos develop generalized edema associated with heart failure. Based upon persistent expression of MLC2a in the hearts of RXR $\alpha^{-/-}$ embryos, Dyson et al. (39) hypothesized that lack of RA signaling results in ventricular "atrialization" such that full differentiation and the fetal ventricular phenotype never occurs.

Our data show that ventricular development and its ultimate phenotype are sensitive to excess RA signaling as well. The initial embryonic and persistent high levels of hRAR $\alpha \mathrm{CB}$ expression in the neonate, juvenile, and adult myocardium evokes progressive and dose-dependent effects leading eventually to heart failure. However, the timing of exposure is critical to the phenotype as postnatal expression of hRAR $\alpha \mathrm{CB}$ (as occurs for the $\alpha$-MyHC-driven transgene) is not deleterious.

Table V. End-systolic Echocardiographic Indices

\begin{tabular}{|c|c|c|c|c|}
\hline \multirow[b]{2}{*}{ End-systolic } & \multicolumn{2}{|c|}{ Baseline } & \multicolumn{2}{|c|}{ Dobutamine } \\
\hline & Control & Line 30 & Control & Line 30 \\
\hline \multicolumn{5}{|c|}{$\begin{array}{l}\text { Pressure-dimension } \\
\text { relationship }\end{array}$} \\
\hline Slope & 41 & 16 & 36 & 15 \\
\hline $\mathrm{y}$-intercept & 39 & $56^{*}$ & $78^{*}$ & 74 \\
\hline \multicolumn{5}{|c|}{$\begin{array}{l}\text { HR-corrected velocity } \\
\text { of fiber shortening } \\
\text { end-systolic wall } \\
\text { stress relationship }\end{array}$} \\
\hline Slope & -0.0096 & -0.0082 & $-0.10^{*}$ & $-0.016^{\S}$ \\
\hline$y$-intercept & 3.2 & $2.1 *$ & $5.5^{*}$ & $2.9^{\ddagger}$ \\
\hline
\end{tabular}

${ }^{*} P<0.05$ versus control mice at baseline; ${ }^{\ddagger} P<0.05$ versus transgenic mice at baseline; ${ }^{\S} P<0.05$ versus control mice during dobutamine treatment. Statistical comparisons were used on analysis of covariance using a one/two way ANOVA.
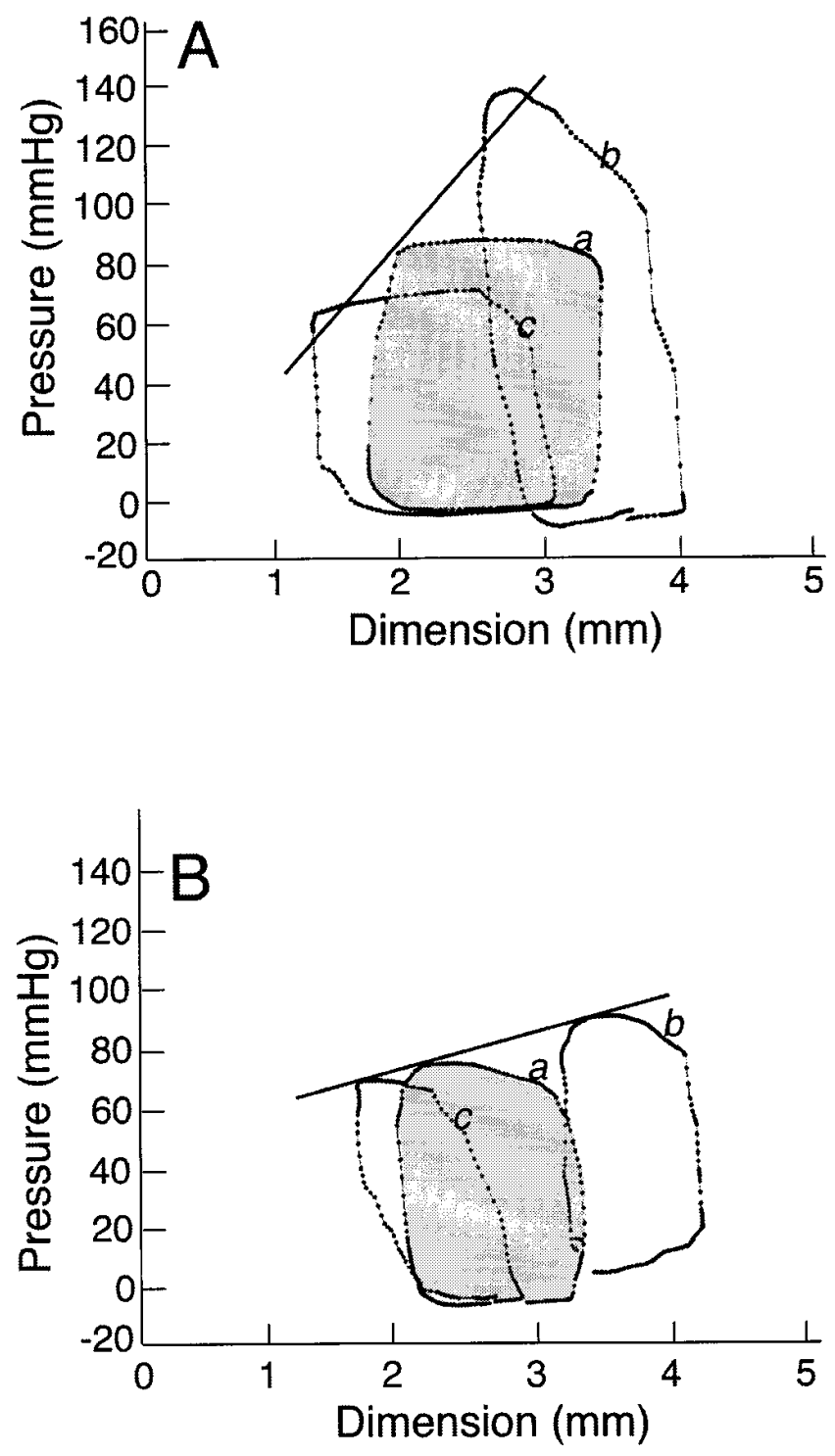

Figure 8. Representative pressure-dimension loops from $(A)$ control and $(B)$ line 30 transgenic animals. In each mouse, pressure-dimension loops were generated during three different conditions: $(a)$ at baseline, no pharmacologic intervention (filled loops); (b) during intravenous phenylephrine infusion to increase left ventricular afterload; and (c) during nitroprusside infusion to decrease left ventricular afterload (see Methods). The area subtended by each of the three loops (an index of total left ventricular stroke work) in line 30 is less than control. The pressure-dimension line generated from data pairs at end-systole is also less steep in line 30 compared to control.

In contrast to a lack of RA signal that prevents full expression of the fetal ventricular phenotype, perhaps continuous retinoid-mediated signaling inhibits complete activation of the adult ventricular phenotype and maintains a fetal ventricle. The $\beta$-MyHC promoter that drives transgene expression does not downregulate appropriately in these mice even though the surviving lines are well below the copy number threshold at which aberrant regulation was observed (31); it should be noted that expression of this promoter is characteristic of the fetal ventricle only. It is also possible that the fetal molecular phenotype merely reflects the hypertrophic response and it is likely that a combination of these factors come into play in 
these animals. Studies in progress that focus on the precise temporal development of the phenotype and the expression of endogenous $\alpha$ - and $\beta$-MyHC, both pre- and postnatally, may help delineate between these and other hypotheses.

The data presented are significantly different from those seen in classical animal teratology $(10,12)$ and human retinoic acid embryopathy (11), which typically produce a variety of structural malformations of the heart including septal and outflow tract defects. The structural changes then produce functional deficits in the heart. In contrast, in these experiments, the transgenic defect is primarily functional with the structural abnormalities in the atria, the trabeculae and papillary muscles occurring secondarily. Two major factors that may contribute to the observed differences are the timing and kinetics of exposure. Transgene transcription is concomitant with onset of contractile protein synthesis in the heart tube. The greatest transcriptional activity and hence the highest retinoid signal may occur after the critical period (10). Thus the heart's maximum sensitivity to retinoid signaling may have occurred earlier during cardiogenesis. Furthermore, the kinetics of exposure are different. The transgenic signal represents a chronic retinoid signal whereas teratogenesis results from an acute, high level exposure. While it is possible that sufficiently high transgene copy number could approximate those levels, the results would most likely be lethal and hence escape detection. Although one high copy number (150 copies) line was established, litter sizes were small, the F1 animals too ill to breed and the line nonviable.

Ventricular dilation with poor systolic function, the hallmark of a DCM, distinguish it from hypertrophic cardiomyopathy. DCM exhibits decompensating chamber dilation while hypertrophic cardiomyopathy is characterized by diastolic dysfunction in the face of enhanced systolic function $(1,40)$. Continued overexpression of $\mathrm{hRAR} \alpha \mathrm{CB}$ in the mouse ventricle correlates with decreased systolic performance and contractile function. Progressive impairment of LV function correlates with gene dosage; line 30 hearts were severely dysfunctional while line 32 hearts were only modestly impaired. Furthermore, line 30 mice exhibited poor in vivo LV contractility, again, a definitive feature of DCM in humans. Finally, right ventricular dilation was readily apparent by echocardiographic analyses, the first time, to our knowledge, that this has been observed in a mouse model.

While changes in the more traditional indices (i.e., shortening fraction, cardiac output, $+d P / d t)$ reflect both changes in contractility and loading conditions, changes in end-systolic indices reflect altered contractility alone. Therefore, to extend the physiologic data, the end-systolic stress shortening and pressure-volume relationships, which are useful measures of left ventricular contractility, were determined in vivo. The data confirm that contractility is severely impaired and suggest a potential role for RA, either directly or indirectly, in regulating expression of contractile proteins during ventricular development. Furthermore, the $\beta-\mathrm{MyHC}-\mathrm{hRAR} \alpha \mathrm{CB}$ transgene is also expressed in a subset of skeletal muscle fibers (Colbert, M., unpublished observations). Experiments are in progress to determine whether retinoids affect contractile protein gene expression in skeletal muscle as well.

The mechanistic basis for RA-mediated DCM remains to be determined. The phenotype may result from the direct action of hRAR $\alpha \mathrm{CB}$ on unique target genes during development. These interactions could have positive or negative tran- scriptional effects or act indirectly by posttranscriptional mechanisms. Alternatively, excess hRAR $\alpha \mathrm{CB}$ could act in a dominant negative fashion, either as a sink for transcriptional activators such as CBP/P300 (41), or by sequestration of RXRs, necessary components for transduction of other nuclear hormone signals. A case can be made for coregulatory signaling of RA and thyroid hormone in the heart. SERCA, $\alpha$-skeletal actin, $\alpha-M y H C$, and $\operatorname{SmN}$, a gene that encodes a tissue specific splicing protein, show co-regulation by both nuclear receptors (42-44). Developmental regulation of the $\alpha$ and $\beta$-MyHC promoters and the role thyroid hormone plays in this process have been extensively documented (see reference 45 for review). Increased cardiac expression of $\mathrm{TR} \alpha_{1}$ and $\mathrm{TR} \alpha_{2}$ has been noted in cases of thyroid hormone deficiency (46). This association was particularly intriguing as DCM in humans is one consequence of hypothyroidism (47). Since the transgenic $\beta$-MyHC promoter fails to downregulate in these animals, receptor transcript levels in these hearts were examined; however, no changes in endogenous levels of either $\operatorname{TR} \alpha_{1}$ or $\mathrm{TR} \alpha_{2}$ could be detected (Colbert, M., and J. Robbins, unpublished observations).

These transgenic mouse lines may provide a useful model for human DCM and heart failure because both mild as well as moderately severe phenotypes are represented. For example, the mice could be used for testing pharmacologic agents for altering cardiac inotropy or slowing or reversing cardiomyopathic properties. Alternatively, the mice can be used in molecular studies as reagents for exploring downstream targets of RA signaling. These studies may provide further insight into RA's actions as well as additional clues concerning the etiology of some types of idiopathic DCM.

\section{Acknowledgments}

We thank Nazeena Alvi for help with animal husbandry, David Hellard and Michelle Nieman for technical assistance, and Katherine Yutzey and Steve Schwartz for helpful comments.

This work was supported by a National Institutes of Health grant HL-55904 and American Heart Association grant SW-95-11 to M. Colbert and National Institutes of Health grants HL56370, HL41496, HL22619, HL52318, and HL56620 to J. Robbins.

\section{References}

1. Patterson, J.H., and K.J. Adams. 1996. Pathophysiology of heart failure: changing perceptions. Pharmacotherapy. 16:27S-36S

2. Vikstrom, K.L., and L.A. Leinwand. 1996. Contractile protein mutations and heart disease. Curr. Opin. Cell Biol. 8:97-105.

3. Muntoni, F., L. Wilson, G. Marrosu, M.G. Marrosu, C. Cianchetti, L. Mestroni, A. Ganau, V. Dubowitz, and C. Sewry. 1995. A mutation in the dystrophin gene selectively affecting dystrophin expression in the heart. J. Clin. Invest. 96:693-699.

4. Fu, Y.H., A. Pizzuti, R. Fenwick, Jr., J. King, S. Rajnarayan, P.W. Dunne, J. Dubel, G.A. Nasser, T. Ashizawa, P. de Jong, et al. 1992. An unstable triplet repeat in a gene related to myotonic muscular dystrophy. Science (Wash. DC). 255:1256-1258.

5. Arber, S., J.J. Hunter, J. Ross, Jr., M. Hongo, G. Sansig, J. Borg, J.-C. Perriard, K.R. Chien, and P. Caroni. 1997. MLP-deficient mice exhibit a disruption of cardiac cytoarchitectural organization, dilated cardiomyopathy, and heart failure. Cell. 88:393-403.

6. Milner, D.J., G. Weitzer, W. Tran, A. Bardley, and Y. Capetanaki. 1996. Disruption of muscle architecture and myocardial degeneration in mice lacking desmin. J. Cell Biol. 134:1255-1270.

7. Chalifour, L.E., M.L. Gomes, N. Wang, and A. Mes-Masson. 1990. Polyoma large T-antigen expression in heart of transgenic mice causes cardiomyopathy. Oncogene. 5:1719-1726.

8. Huen, D.S., A. Fox, P. Kumar, and P.F. Searle. 1993. Dilated heart failure in transgenic mice expressing the Epstein-Barr virus nuclear antigen-leader 
protein. J. Gen. Virol. 74:1381-1391.

9. Iwase, M., M. Uechi, D.E. Vatner, K. Asai, R.P. Shannon, R.K. Kudej, T.E. Wagner, D.C. Wight, T.A. Patrick, Y. Ishikawa, et al. 1997. Cardiomyopathy induced by cardiac $\mathrm{G}_{\mathrm{s}} \alpha$ overexpression. Am. J. Physiol. 272:H585-H589.

10. Shenefelt, R.E. 1972. Morphogenesis of malformations in hamsters caused by retinoic acid: relation to dose and stage at treatment. Teratology. 5: 103-118.

11. Lammer, E.J., D.T. Chen, R.M. Hoar, N.D. Agnish, P.J. Benke, J.T. Braun, C.J. Curry, P.M. Fernhoff, A.W. Grix, I.T. Lott, et al. 1985. Retinoic acid embryopathy. N. Engl. J. Med. 313:837-841.

12. Wilson, J.G., and J. Warkany. 1949. Aortic-arch and cardiac anomalies in the offspring of vitamin A deficient rats. Am. J. Anat. 85:113-155.

13. Sucov, H.M., E. Dyson, C.L. Gumeringer, J. Price, K.R. Chien, and R.M. Evans. 1994. RXR $\alpha$ mutant mice establish a genetic basis for vitamin A signaling in heart morphogenesis. Genes Dev. 8:1007-1018.

14. Kastner, P., J.M. Grondona, M. Mark, A. Gansmuller, M. LeMeur, D. Decimo, J.-L. Vonesch, P. Dollé, and P. Chambon. 1994. Genetic analysis of RXR $\alpha$ developmental function: convergence of RXR and RAR signaling pathways in heart and eye morphogenesis. Cell. 78:987-1003.

15. Mendelsohn, C., D. Lohnes, D. Decimo, T. Lufkin, M. LeMeur, P. Chambon, and M. Mark. 1994. Function of the retinoic acid receptors (RARs) during development (II). Multiple abnormalities at various stages of organogenesis in RAR double mutants. Development (Camb.). 120:2749-2771.

16. Wu, J., M. Garami, T. Cheng, and D.G. Gardner. 1996. 1,25 (OH $)_{2}$ Vitamin $\mathrm{D}_{3}$ and retinoic acid antagonize endothelin-stimulated hypertrophy of neonatal rat cardiac myocytes. J. Clin. Invest. 97:1577-1588.

17. Zhou, M.D., H.M. Sucov, R.M. Evans, and K.R. Chien. 1995. Retinoiddependent pathways suppress myocardial cell hypertrophy. Proc. Natl. Acad. Sci. USA. 92:7395-7391.

18. Chambon, P. 1996. A decade of molecular biology of retinoic acid receptors. FASEB (Fed. Am. Soc. Exp. Biol.) J. 10:940-954.

19. Mangelsdorf, D.J., and R.M. Evans. 1995. The RXR heterodimers and orphan receptors. Cell. 83:841-850.

20. Damm, K., R.A. Heyman, R.A. Umesono, and R.M. Evans. 1993. Functional inhibition of retinoic acid response by dominant negative retinoic acid receptor mutants. Proc. Natl. Acad. Sci. USA. 90:2989-2993.

21. Cash, D.E., C.B. Bock, K. Schughart, E. Linney, and T.M. Underwood. 1997. Retinoic acid receptor $\alpha$ function in vertebrate limb skeletogenesis: a modulator of chondrogenesis. J. Cell Biol. 136:445-457.

22. Saltou, M., S.T. Tanaka, K. Shimouchi, E. Fuchs, S. Narumiya, and A. Kakizuka. 1995. Inhibition of skin development by targeted expression of a dominant-negative retinoic acid receptor. Nature (Lond.). 374:159-162.

23. Balkan, W., G.K. Klintworth, C.B. Bock, and E. Linney. 1992. Transgenic mice expressing a constitutively active retinoic acid receptor in the lens exhibit ocular defects. Dev. Biol. 151:622-625.

24. Palermo, J., J. Gulick, M. Colbert, J. Fewell, and J. Robbins. 1995. Transgenic remodeling of the contractile apparatus in the mammalian heart. Circ. Res. 78:504-509.

25. Colbert, M.C., M.L. Kirby, and J. Robbins. 1996. Endogenous retinoic acid signaling colocalizes with advanced expression of the adult smooth muscle myosin heavy chain isoform during development of the ductus arteriosus. Circ. Res. 78:790-798.

26. Sheehan, D.C., and B.B. Hrapchak. 1980. Processing, sectioning, and general staining considerations for tissues. Theory and Practice of Histotechnology. Second ed. D.C. Sheehan and B.B. Hrapchak, editors. C.V. Mosby Co., St. Louis. 59-136.

27. Jones, W.K., I.L. Grupp, T. Doetschman, G. Grupp, H. Osinsk, T.E. Hewett, G. Boivin, J. Gulick, W.M. Ng, and J. Robbins. 1996. Ablation of the murine $\alpha$ myosin heavy chain gene leads to dosage effects and functional deficits in the heart. J. Clin. Invest. 98:1906-1917.

28. Gulick, J., T.E. Hewett, R. Klevitsy, S.H. Buck, R.L. Moss, and J. Robbins. 1997. Transgenic remodeling of the regulatory myosin light chains in the mammalian heart. Circ. Res. 80:655-664.

29. Lorenz, J., and J. Robbins. 1997. Measurement of intraventricular pres- sure and cardiac performance in the intact closed chest anesthetized mouse. Am. J. Physiol. 272:H1137-H1146.

30. Ng, W.A., I.L. Grupp, A. Subramaniam, and J. Robbins. 1991. Cardiac myosin heavy chain mRNA expression and myocardial function in the mouse heart. Circ. Res. 69:1745-1750.

31. Knotts, S., H. Rindt, and J. Robbins. 1995. Position independent expression and developmental regulation is directed by the $\beta$ myosin heavy chain gene's 5' upstream region in transgenic mice. Nucleic Acids Res. 23:3301-3309.

32. Knotts, S. 1995. In vivo regulation of the mouse $\beta$ myosin heavy chain gene. Ph.D. thesis. University of Cincinnati, School of Medicine. 220 pp.

33. Izumo, S., A.M. Lompre, R. Matsuoka, G. Koren, and K. Schwartz 1987. Myosin heavy chain messenger RNA and protein isoform transitions during cardiac hypertrophy: interaction between hemodynamic and thyroid hormone-induced signals. J. Clin. Invest. 79:970-977.

34. Azizi, C., P. Bouiossou, F. Galen, A. Lattion, M. Lartigue, and A. Carayon. 1995. Alterations in atrial natriuretic peptide gene expression during endurance training in rats. Eur. J. Endocrinol. 133:361-365.

35. Schwartz, K., D. de la Bastie, P. Bouveret, P. Oliviero, S. Alonso, and M. Buckingham. 1986. $\alpha$-Skeletal muscle actin mRNA accumulates in hypertrophied adult rat hearts. Circ. Res. 59:551-555.

36. Mercadier, J.J., A.M. Lompre, P. Duc, K. R. Boheler, J.B. Fraysse, C. Wisnewsky, P.D. Allen, M. Komajda, and K. Schwartz. 1990. Altered sarcoplasmic reticulum $\mathrm{Ca}^{2+}$-ATPase gene expression in the human ventricle during end-stage heart failure. J. Clin. Invest. 85:305-309.

37. Schwinger, R.H., M. Bohm, U. Schmidt, P. Karczewski, U. Bavendiek, M. Flesch, E.G. Krause, and E. Erdmann. 1995. Unchanged protein levels of SERCA II and phospholamban but reduced $\mathrm{Ca}^{2+}$ uptake and $\mathrm{Ca}^{2+}$-ATPase activity of cardiac sarcoplasmic reticulum from dilated cardiomyopathy patients compared with patients with nonfailing hearts. Circulation. 92:3220-3228.

38. Kastner, P., M. Mark, N. Ghyselinck, W. Krezel, V. Dupé, J.M. Grondona, and P. Chambon. 1997. Genetic evidence that the retinoid signal is transduced by heterodimeric RXR/RAR functional units during mouse development. Development (Camb.). 124:313-326.

39. Dyson, E., H.M. Sucov, S.W. Kubalak, G.W. Schmid-Schönbein, F.A DeLano, R.M. Evans, J. Ross, Jr., and K.R. Chien. 1995. Atrial-like phenotype is associated with embryonic ventricular failure in retinoid $\mathrm{X}$ receptor $\alpha-1-$ mice. Proc. Natl. Acad. Sci. USA. 92:7386-7390.

40. Francis, G.S., K. McDonald, C. Chu, and J.N. Cohn. 1995. Pathophysiologic aspects of end-stage heart failure. Am. J. Cardiol. 75:11A-16A.

41. Kitabayashi, I., R. Eckner, Z. Arany, R. Chiu, G. Gachelin, D.M. Livingston, and K.K. Yokoyama. 1995. Phosphorylation of the adenovirus E1Aassociated $300 \mathrm{kDa}$ protein in response to retinoic acid and E1A during differentiation of F9 cells. EMBO (Eur. Mol. Biol. Organ.) J. 14:3496-3509.

42. Gerrelli, D., J.D. Huntriss, and D.S. Latchman. 1994. Antagonistic effects of retinoic acid and thyroid hormone on the expression of the tissue-specific splicing protein $\mathrm{SmN}$ in a clonal cell line derived from rat heart. J. Mol. Cell. Cardiol. 26:713-719.

43. Muscat, G.E., R. Griggs, M. Downes, and J. Emery. 1993. Characterization of the thyroid hormone response element in the skeletal alpha-actin gene: negative regulation of $\mathrm{T} 3$ receptor binding by the retinoid $\mathrm{X}$ receptor. Cell Growth Differ. 4:269-279.

44. Rohrer, D.K., R. Hartong, and W.H. Dillman. 1991. Influence of thyroid hormone and retinoic acid on slow sarcoplasmic reticulum $\mathrm{Ca}^{2+}$ ATPase and myosin heavy chain $\alpha$ gene expression in cardiac myocytes. J. Biol. Chem. 266:8638-8646.

45. Morkin, E. 1993. Regulation of myosin heavy chain genes in the heart. Circulation. 87:1451-1460.

46. Balkman, C., K. Ojamaa, and I. Klein. 1992. Time course of the in vivo effects of thyroid hormone on cardiac gene expression. Endocrinology. 130: 2001-2006.

47. Ladenson, P.W., S.I. Sherman, K.L. Baughman, P.E. Ray, and A.M. Feldman. 1992. Reversible alterations in myocardial gene expression in a young man with dilated cardiomyopathy and hypothyroidism. Proc. Natl. Acad. Sci. USA. 89:5251-5255. 